\title{
Problems in developing bilingual education programs in Switzerland
}

\author{
DANIEL STOTZ and FRANZ ANDRES
}

Abstract

On the basis of the preceding contributions to this issue, this paper presents the project 'Unterrichtssprache Französisch/Deutsch' (UFD), which was undertaken by an interdisciplinary group of researchers and educators in Switzerland. Its goals are to improve the level of communicative competence of Swiss learners in a second national language and thereby to attempt to enhance the rapports between the various language groups. An outline of the concepts of communicative competence and individual (functional) bilingualism serves as a backdrop against which current models of bilingual (immersion) education are presented. The paper reports the discussions and suggestions of a symposium in Berne that brought together academics, educators and interested parties with a view to implementing forms of bilingual education in Switzerland.

\section{Aim and objectives of the project}

It was pointed out in the preface to this issue and in the introductory article on language relations in Switzerland that there is a discrepancy between the official multilingualism of the country and the widespread perceptions of a lack of competence in LN2 and of a rift opening up between the French and German-speaking communities in particular. This is the case despite the fact that a sizeable number of lessons in school are given over to the tuition of LN2. In contrast, English, although learnt only from age 14 or 15 on and for fewer hours per week than any LN2, is often cited, especially by younger Swiss nationals, as a preferred means for intranational communication. The reason for this is that, apart from being the language of youth 
culture, English is perceived as an internationally more viable language than French or German, and the motivation to learn it is therefore greater (Dürmüller 1989; Gretler 1988: 36ff.). ${ }^{1}$

But what could be done to encourage students to learn LN2 and to learn it more successfully? There now seems to be a consensus among education authorities, educators and parents with respect to the age at which LN2 instruction should be begun: the traditional age of 13 has been found to be too late. The initiative for an earlier start goes back to 1966 (Zeitz 1989: 360), when the Canton of Zürich decided to run trial classes with early French. In 1974 the EDK (cf. preface) issued a report recommending the earlier start nationwide (Grade 4 or 5). It argued that in puberty inhibitions could in effect impede the children's learning processes and that an earlier start would allow a more playful and use-oriented approach (1974: 16/17). The realization of the reform (cf. preface) took 15 years although it must be said that only a decision in favour of the measure has been made in some cantons as yet and implementation will not take place until the early nineties. The results of the measure are not conclusive yet. Therefore the search for models to improve LN2 competence should and does indeed continue (EDK 1987).

The UFD project must be seen within the context of that search. Its basic goal is to broaden the scope of LN2 tuition by conducting instruction in non-language subjects in the target language, thus providing more time and opportunities for the exposure to and the active use of LN2.

There are two objectives to the project:

a) to improve the level of competence in LN2 in a more effective way than existing forms of tuition, and

b) by an improved ability to communicate in a second national language, to work towards a better understanding between the language groups (cf. below, 3.2.4).

In order to set these objectives in the proper perspective we need to discuss briefly two concepts which are inherent to them, viz. communicative competence and individual (functional) bilingualism.

\section{The concepts of communicative competence and functional bilingualism}

It is significant to note that the perceived lack of competence in LN2 was paraphrased as a lack of fluency by the respondents to the Weltwoche 
survey (Heller 1987: 37, cited in Andres, this issue). From the discussion above, we may conjecture that although Swiss students spend a great deal of time in classrooms where an LN2 is taught as a subject and although their knowledge of grammatical rules and exceptions may be on a par with curriculum objectives, many of them seem to find it hard to employ their knowledge in language contact situations.

Such a disparate self-assessment may be accommodated by a modular view of communicative competence. In fact, there have been attempts in the literature on language teaching and testing to come to terms with differential learning outcomes. For instance, Canale and Swain's position paper (1980) set up a three-way distinction between (a) grammatical competence, (b) sociolinguistic competence, and (c) discourse competence; (a) relates to the mastery of the language code, its elements, features and rules such as vocabulary, word formation, sentence formation, pronunciation, spelling, etc.; (b) relates to the socially appropriate use of utterances in various contexts; (c) refers to the mastery of how to combine grammatical forms and meanings into cohesive and coherent sequences. Additionally, Canale and Swain claim, native speakers master a range of strategies to compensate for breakdowns in communication. This component, called strategic competence, is conceptualized as lying outside of communicative competence proper.

However, a simple lack of discourse competence could not be held responsible for all the problems non-native speakers face when trying to take part in a conversation. For, in order to be actively cohesive and coherent, speakers must first gain access to the conversational floor ${ }^{2}$ as well as get and hold their interlocutors' attention. Canale and Swain subsume 'commonly used floor-holding strategies' under strategic competence (1980: 31). However, the ability to use one's linguistic and paralinguistic skills in real-time interaction cannot be relegated to a strategic component whose main function is to cope with breakdowns. Separating linguistic knowledge from the knowledge as to how it is used in interaction amounts to a position that falls victim to the same idealized concept of competence that was rejected by Hymes (1972) in his critique of the Chomskyan notion of competence. Therefore, strategic competence should be conceptualized as part and parcel of the native speaker's communicative competence.

There is a tendency in second language acquisition research to trivialize the complexities of the language user's knowledge and abilities in an attempt to arrive at statistically significant results. ${ }^{3} \mathrm{~A}$ different approach 
to communicative competence is suggested by work done in the field of interactional sociolinguistics. ${ }^{4}$ Of particular relevance is the research done by John Gumperz as well as by Frederick Erickson and their respective co-workers. Erickson's tentative model of a 'practical speaker-hearer' (1986) encompasses at least two broad kinds of knowledge. Institutionalized knowledge includes speech-community-specific rules corresponding to strictly linguistic (phonological, syntactic, lexical) and discourseorganizational competences. In addition, institutionalized knowledge consists of

culturally learned patterns for the uses of speech, e.g. knowledge of register in relation to situations of use, schemata of expectation for patterns of sequencing in customary activities, cooccurrence princples in the organization of customary discourse routines and of connected sets of speech acts, and schemata of interpretation for momentary communicative acts. (Erickson 1986: 294)

Institutionalized knowledge goes beyond Canale and Swain's notion of communicative competence, particularly on the dimension of cultural knowledge. However, it still only captures one order of knowledge and skill a practical speaker-hearer must possess. Additionally, so-called emergent knowledge is needed to solve the 'problems faced ... continually by speakers and hearers engaged in face-to-face interaction':

The interlocutors confront the unique exigencies of the moment as they conduct oral discourse together in the real time of actual performance. (Erickson 1986: 295)

Emergent knowledge concerns 'the domain of praxis in reasoning, the capacity to create sense in addition to following rules, to go beyond what is culturally learned and, in the midst of the fortuitous contingency of the moment, to play interaction by ear' (1986: 296). The concept of emergent competence is thus far more comprehensive than the notion of strategic competence. It also covers certain aspects of fluency as they have been described by Charles Fillmore, for example 'the ability to talk at length with few pauses' and the ability to be 'verbally at ease in many different kinds of conversational settings' (Fillmore 1979: 93).

Canale and Swain's notion of strategic competence is basically a residual category for language learners' techniques of dealing with breakdowns, and thus divorced from a notion of conversational strategies used by native speakers or bilingual persons (cf. Gumperz 1982; Heller and Barker 1988). If such strategies are seen as makeshift, survivalist ways of avoiding communication breakdowns, then we deny the possibility that 
strategic knowledge can be used in culturally specific ways in order to create extra-lexical meaning. As an example, we may think of the practical speaker-hearer's knowledge as to when it may be possible to begin to speak while another participant is talking, i.e. when to intervene. Depending on the situational context and the relationship and status of the participants, intervention may or may not be associated with negative consequences. Knowing how to intervene may be an important skill in exolingual encounters where one participant is handicapped by having to use an L2. Emergent competence is thus needed to deal with the exigencies of real-time interaction in culturally viable ways.

The construct of communicative competence is here seen as encompassing both institutionalized and emergent knowledge and skills. We assume that in both components, grammatical, sociolinguistic, discourse-organizational and strategic abilities interact in complex ways that would have to be the subject of interactional studies in the course of an eventual project evaluation.

As far as the second issue to be discussed here is concerned, that of bilingualism, it may be debatable whether the concerned voices on both sides of the 'rift' are correct when they claim that the language groups in Switzerland are drifting apart (cf. Andres, this issue) or whether, in fact, the mutual difficulty in inter-language group communication has become more noticeable because of greater mobility and media attention. It is by no means certain that this communication was ever unproblematic, or that a lack of direct contact ever actually exposed weaknesses in LN2 competence. Nor can there be any doubt that there has ever been a situation in Swiss history where large sectors of society were functioning bilingually, i.e. a kind of societal bilingualism such as it exists in Paraguay with Spanish and Guaraní. If certain groups such as the Bernese patricians did use two languages customarily, it was because they had vested interests such as the ruling of French-speaking dominions (cf. Fishman 1972).

The goals of LN2 policy in Switzerland must therefore be seen in promoting individual, and not societal, bilingualism. There has always been a demand for language brokers, not just in contact situations along the linguistic borders, but also in the federal civil service and in private companies doing business nationwide and internationally (cf. below, 3.3.1). The increased mobility and communicativity of today's and future society warrant a rise in the need for such individuals. While language brokers need not be perfectly bilingual (such as someone who grew up in a balanced bilingual family environment), they must nevertheless be able to 
function in a range of situations or speech activities (Gumperz 1982), i.e. they need good functional bilingualism.

However, it is not usually possible until late in the process of schooling to specify what these situations might be. There is a certain danger that the concept of functional bilingualism becomes reductionist. This may be the case if we understand 'function' to mean 'get by' or 'survive'. However, having put the concept of communicative competence upon a new foundation, that of institutionalized plus emergent competence, we can now see more clearly where the ulterior objectives will lie. An alternative approach to LN2 tuition as it is envisaged by the UFD project attempts to promote learners' communicative competence, institutionalized and emergent, in order for them to become more functionally bilingual and to be able to act as language brokers in exolingual situations.

The rationale behind an LN2 as the medium of instruction is to broaden the scope of speech activities in which the learners may purposefully use the LN2 within the classroom. They are given the opportunity to negotiate meanings beyond the immediate boundaries of language textbook tasks such as exercises and communication games. While the obvious drawback of such a concept is that communication in the LN2 is still bounded by the school context (cf. Heller, this issue), the range of speech activities to be engaged in is nevertheless broader than in traditional language lessons where the LN2 is the subject of study. ${ }^{5}$

Given that the school system in its present form seems to reach limits with respect to improving the level of LN2 competence, the UFD project does not primarily address itself to that same system. The Federal Constitution requires the cantons to provide obligatory and free schooling under public supervision (Art. 27 2/3). Therefore, even if the school system may not be the most effective medium for achieving a functional form of bilingualism, its task of equipping students with the means with which to master exolingual communication situations, still requires the optimal and most far-reaching framework for LN2 tuition, and this will mean, by extension, a general improvement in LN2 communicative competence.

\section{The symposium}

The working group set up by the Academic Committee of the University of Berne to explore the possibilities of immersion programs in Switzerland soon became aware that French immersion as practised in Canada would 
be difficult to realize in Switzerland. In Canada, for instance, immersion programs came into existence because of parental pressure (Gibson 1984). In Switzerland awareness even of the possibility of such a system was practically non-existent. Therefore, one of the first tasks was to draw attention to forms of education with bilingual competence as an objective.

Taking into account the conservative nature of many of the Swiss, a radical model such as 'Early Total Immersion' could in all likelihood only be a long-term proposition. The way towards such a program would probably consist of smaller steps in the form of less radical models. A number of these were examined and their adaptability for a Swiss context considered. However, mistrust in things foreign made it imperative for successful models already in place in Switzerland to be found. This proved rather more difficult, but eventually two instances of language learning via immersion were discovered. On the basis of this preparatory research a symposium was held at the University of Berne with two aims: firstly, to assess the feasibility of bilingual education in Switzerland with the longterm goal of an Early Immersion program, and, secondly, if that proved feasible, to work towards propagating the idea in the circles which would support the project and the underlying philosophy, i.e. improving relationships across language borders.

\subsection{The participants}

The symposium reflected the academic as well as the practical nature of the project. The participants could be grouped into three categories, as in Figure 1:

1. The 'experts' were researchers from the fields of language contact and language conflict, representatives of the academic disciplines concerned with schooling and child development, and educators and administrators with practical experience in bilingual education. The contribution of this group was to provide the theoretical background in which bilingual schooling in a multilingual setting would have to be seen and to present the practical experiences derived from existing models.

2. The 'administrators' were, on the one hand, politicians and educational administrators, who would have to help put the wheels for realization in motion. On the other hand, the group consisted of political and legal experts. The task for these participants was to discuss the framework for possibilities and limitations of potential models within the 


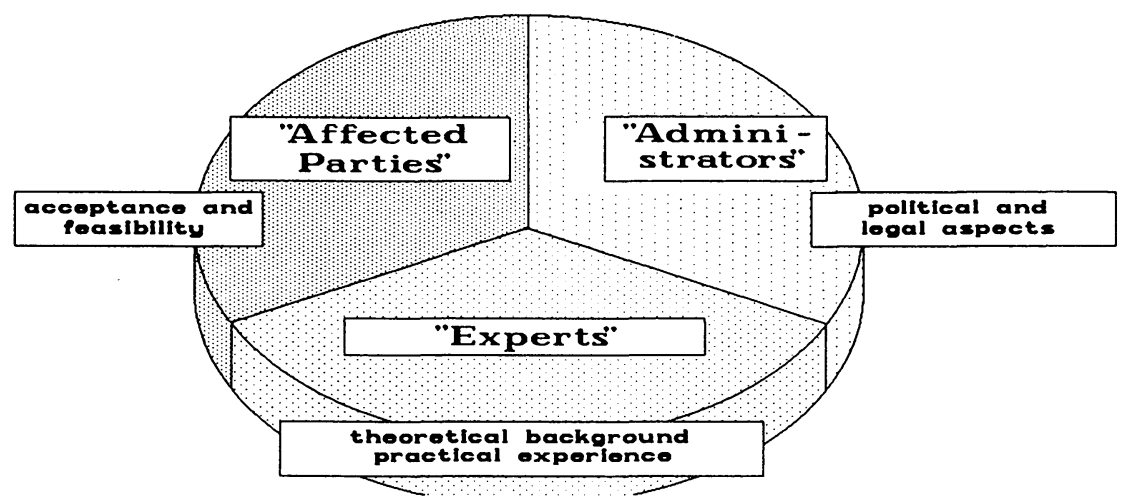

Figure 1. Participants and their backgrounds (Symposium on bilingual education, Berne, 1988)

Swiss educational system and the legal aspects of bilingual education (cf. Keller, this issue).

3. The 'affected parties' consisted of parents, headmasters, teachers and pupils, either with practical experience in bilingual education or with an interest in its realization in Switzerland. They were to gauge the feasibility and acceptability of such models.

\subsection{The models}

The models presented were chosen to reflect two parameters: firstly, the age of the children and their previous exposure to LN2, and, secondly, the intensity of exposure to the target language in the program. Table 1 presents an overview of the models which will be discussed below. The summaries will provide the reader with the social background, the age group it is aimed at, the form bilingual education takes, and what practical suggestions could be derived from them for Swiss models of bilingual education.

We will now discuss the models in an order which reflects the age of the students at the beginning of the program.

\subsubsection{Language learning at an early age: the 'Méthode R.E.M.I.' ${ }^{\prime}$}

The Méthode R.E.M.I. is practised at the private Deutsche Schule (German School) in Geneva. The students taught with this method are 
Table 1. Overview of models for discussion at the symposium

\begin{tabular}{llll}
\hline $\begin{array}{l}\text { Intensity } \\
\text { Age }\end{array}$ & $\begin{array}{l}\text { 'monolingual' } \\
\text { tuition only } \\
\text { in L2 }\end{array}$ & $\begin{array}{l}\text { L1 and L2 } \\
\text { mixed }\end{array}$ & $\begin{array}{l}\text { L2 restricted } \\
\text { to specific } \\
\text { lessons and/or } \\
\text { subjects }\end{array}$ \\
\hline $\begin{array}{l}\text { Early, no } \\
\text { previous L2 } \\
\text { instruction }\end{array}$ & $\begin{array}{l}\text { Early Total } \\
\text { Immersion }\end{array}$ & $\begin{array}{l}\text { Early Partial } \\
\text { Immersion }\end{array}$ & $\begin{array}{l}\text { Early L2 } \\
\text { Training }\end{array}$ \\
$\begin{array}{l}\text { Models } \\
\text { Ecole La }\end{array}$ & not discussed & R.E.M.I. \\
$\begin{array}{l}\text { Tanne } \\
\text { previous L2 } \\
\text { instruction }\end{array}$ & $\begin{array}{l}\text { Late Total } \\
\text { Immersion }\end{array}$ & $\begin{array}{l}\text { Late Partial } \\
\text { Immersion }\end{array}$ & $\begin{array}{l}\text { Extended L2 } \\
\text { Instruction }\end{array}$ \\
& $\begin{array}{l}\text { Dixième Anné } \\
\text { Linguistique }\end{array}$ & $\begin{array}{l}\text { Lycé Franco- } \\
\text { allemand, Buc }\end{array}$ & $\begin{array}{l}\text { Goffs School } \\
\text { geography in }\end{array}$ \\
& & French
\end{tabular}

children of a mainly middle class background, or as one of the presenters at the symposium put it, 'des enfants d'un milieu favorisé'.

R.E.M.I. is an audiovisual course for German, French and English (from the 5th grade on), consisting of 80 units and is designed to cater for children aged from seven to eleven. In every unit the materials are practised in ever increasing independence from repetition to active reproduction. The way in which this happens is based on the methodological concept laid down in the motto of the method, 'On ne sait bien que ce que l'on a fait', i.e. one only learns by doing. The emphasis of the exercises, therefore, is on activities oriented along the lines of the children's interests and their developmental level; the activities used include games, songs, role plays, mime, drama and conversation.

In view of the limited time scale - the course with three 45 minute lessons per week takes 4 years - the children, according to the organizers, acquire an impressively good pronunciation, which could be expected, but also develop the ability to use the language learned in the course spontaneously and in many cases without being prompted to do so.

The following aspects are considered crucial for the success of the program. Firstly, the activities must be suitable for the cognitive level of the children and should involve the 'whole person' in the form of games, miming and songs, etc. Secondly, the teachers must be aware of the pitfalls of the audiovisual method, i.e. the rigidity of the course, the possibility of 'situations purement scolaires', i.e. of very school-like situations somewhat 
unrelated to reality, and be prepared to try and counteract these problems by an intensive involvement with the children.

One may question the validity of the audiovisual method in general and the comparatively conservative way in which it is practised in this model. The rationale for including R.E.M.I. was to demonstrate that younger children can be successfully taught a foreign language, even in a limited amount of time. It was considered necessary to make this point at the time because the symposium took place during a period when early LN2 programs were the topic of referenda in Eastern Switzerland; one of the arguments against these programs was that young children were overtaxed by the task of having to learn another language before having learnt their own language 'properly' (sic) (cf. Andres 1988: 42ff.).

\subsection{2 'Total Immersion' in French: the Ecole La Tanne in the Bernese Jura}

The Ecole La Tanne is a small, rural school in a remote area of the French-speaking part of the Bernese Jura. It has two teachers, one for grades 1 to 4 , the other for grades 5 to 9 , both Romands. The entire curriculum is taught in French according to the guidelines for state primary schools and with the materials used in French-speaking Berne. The pupils from the catchment area are mainly farmers' children, who receive most of their schooling here, before taking on apprenticeships in the regional centers of Tramelan, Sonceboz, Saignelégier, etc. In other words, it is a typical rural Romand school, with one difference: the pupils' mother tongue and the language spoken in the playground is German. The reason for this is that the settlements in the school's catchment area are inhabited by German-speaking Mennonites who, as a religious minority, were forced by the Bernese protestants to emigrate from their homes in the Emmental (some as far as North America) and were granted asylum in this area by the prince-abbots who controlled the region (Grosjean 1971).

Until approximately 14 years ago the school was privately run, and tuition was in German. The problem, however, was that when the children left school they encountered great difficulty with the linguistic demands made on them by their French-speaking environment. To facilitate the transition from the isolated German community to the wider francophone area it was decided to change the language of instruction to 
French. The system seems to be working quite well. On balance it can be said that those children who begin junior school in La Tanne after one or two years at kindergarten in nearby (French-speaking) Tramelan find that they can cope with the demands of the school environment without great difficulty; the task is somewhat more formidable for their peers who do not have that benefit.

According to the two teachers, some adaptations have to be made to allow the children to make progress in a school environment which essentially is not designed for them: for instance, German as well as French lessons are based on textbooks which assume that the pupils are of French mother tongue. Therefore, the teachers have to give the children more help to cope with the comparatively complex vocabulary of French language textbooks. For German they are given additional reading materials. Understandably, those subjects involving language of a comparatively complicated nature, for example History, cause more problems than others like Maths where a less sophisticated level of language is needed to cope with the subject matter.

In general the objectives set by the cantonal syllabus can be reached although at a somewhat slower pace and with a greater effort. This can be a problem in the fundamentally content-oriented Swiss educational system. In our preliminary research we were able to observe a fairly impressive degree of functional bilingualism in the senior school, although the achievements are far from uniform. ${ }^{8}$ Furthermore, it was interesting to note how disciplined the children were in using French in the classroom, even for private conversation. In certain cases, sometimes even when they were excited (for example when playing ball in the playground) French interjections were also used.

Ecole La Tanne sheds light on four interesting aspects:

a) It shows that a total immersion situation provides a setting in which an impressive standard of LN2 competence can be acquired. In the case of La Tanne, the pupils attain a good level of functional bilingualism, apparently without compromising their achievement in the other subjects. b) Those children with an earlier start in a francophone kindergarten can cope with the linguistic demands of the school system more easily than children without kindergarten. Late arrivals (3rd grade and higher) have the greatest difficulties.

c) Even though most models are aimed at, or take place in, a middle class environment (cf. other models) this is not a prerequisite for the success of bilingual education. 
d) Ecole La Tanne, despite its successes, makes it clear that immersion programs are very different from monolingual instruction in the students' mother tongue. Such programs require a special approach on the part of the teachers and materials suited for this particular purpose.

\subsubsection{French as a medium of instruction in selected non-language} subjects: Goffs School in Walthams Cross, Hertfordshire, England

Goffs School is a comprehensive school just outside the northern periphery of Greater London in Walthams Cross. Socio-economically the catchment area of the school is clearly middle class. According to the headmaster, Dr. Hadley, the families are fairly open to international influences, and the children are quite likely to have spent some time traveling abroad, i.e. there is little doubt in the community that proficiency in foreign languages is desirable. The school prides itself on being an 'Oxbridge School', in other words, of having a comparatively large number of students going on to Oxford or Cambridge (Hadley, personal communication).

In the wake of the Franco-German Treaty of Cooperation (1969), which resulted in the bilingual lycées and Gymnasien in France and Germany, a group of British headmasters decided to introduce the system in the UK, too. As a result the so-called 'Section bilingue' at Goffs was formed in the academic year 1973/74. Its aim was to encourage pupils with good results after the first year of French (age 12) to improve their competence by studying certain non-language subjects in French ${ }^{9}$ in addition to regular French courses for two years. In the fourth year French is taught solely in five regular French lessons again, but on a much higher level than in the corresponding grades.

The factors which, according to Hadley, contribute to the success of the system as a whole have already been alluded to above: the area is socioeconomically well suited and not as insular as some other regions in the area with a different social and economic background. The selection of students with the best results in French and then some pupils with good overall results seems to guarantee success.

The results are impressive indeed: at the end of the fourth year the students take General Certificate of Education ' $O$ ' levels, one year earlier than their peers in the regular French course. One year later they go on to do 'half " $A$ " levels'. ${ }^{10}$ Originally full ' $A$ ' levels were successfully at- 
tempted, but it was decided that this resulted in too great an increase in the students' workload.

Seen in terms of applicability in Switzerland, Goffs School represents the most moderate form of bilingual education. Despite being somewhat elitist, it shows that an improvement in L2 competence can be achieved even with a comparatively modest program. Furthermore, as the secretary of the EDK, Moritz Arnet, suggests, such a model could be implemented without any legal problems in Swiss schools on the initiative of the school administrators. It would require the support of parents and would have to be a voluntary program. If these prerequisites were met, the legal question of promotion to the next grade (cf. Keller, this issue) would not pose a problem, either (Arnet, personal communication).

\subsection{4 'Late Total Immersion' in French and German: Dixième Année Linguistique/Fremdsprachliches 10. Schuljahr in the Canton of Fribourg}

The bilingual Canton of Fribourg presents an interesting language contact situation because of its reversal of roles in comparison to the country as a whole: approximately two thirds of the canton are Frenchspeaking, one third is germanophone. In general it can be said that the requirement for the German-speaking minority to be bilingual is greater than vice versa (Pichard 1978: 292, cf. also Andres, this issue).

The inception of the program can be traced to the 500th anniversary of the membership of the Cantons of Fribourg and Solothurn in the Confederation in $1981 .{ }^{11}$ As it stands now, it offers individual students living in the canton the opportunity of spending a year in the other language area after completion of the obligatory nine school years. Hence the name Tenth Linguistic School Year. Students from other cantons can also make use of the system, but have to defray school costs. According to the coordinators the proportion of students from outside the canton is increasing slowly.

The pupils making use of this opportunity can be put into two groups: on the one hand, there are a fair number whose primary motivation is to improve their competence in LN2 as bilingualism in this language border area can be economically beneficial. Especially in the bilingual capital, the city of Fribourg, competence in both French and German can improve job prospects considerably. But, as the federal capital of Berne is well 
within commuting distance, the federal administration also provides interesting career perspectives.

The second group, on the other hand, makes use of the Tenth Linguistic School Year as a waiting period, for example for apprenticeships or before entering schools for which a minimum age is required. The teachers we interviewed in the preliminary stages of our research pointed out that the first group, after initial struggles, usually did very well, reaching an impressive level of competence in LN2. Their integration into the classes was on average good, and they were able to build up interesting contacts on the other side of the language border. The other group, however, predictably did less well and there was little hope except in very few isolated cases that their attitude would change or performance improve in the course of the school year.

The students could also be grouped according to a different criterion, i.e. that of commuting students vs. students living in host families. Although all students are required to fill in questionnaires concerning their experience at the end of the year, no actual assessment of their progress is being made. The organizers feel that this might deter students from taking the option. It is therefore impossible to determine whether and how achievements differ between commuters and boarders.

Interviews, evaluation of the questionnaires and the workshops at the symposium yielded several interesting points:

1) There is a problem of integration for the Romands because of the use of standard and dialect in the school environment. As has been pointed out in this issue (Andres, section 2.2.) standard German is limited to 'head subjects'. Off-record conversation in class and in the playground, crafts and games are conducted in Swiss German. The problem is addressed in introductory meetings at the beginning of the school year, but this is short of providing much help. However, some linguistically talented Romands will also acquire at least a passive understanding of the dialect.

2) In order to achieve an improved level of LN2 competence a certain degree of instrumental motivation is necessary at the beginning. In some cases this will lead to integrative motivation in the course of the school year. ${ }^{12}$

3) Even though there is a tendency towards early exposure to L2 and LN2, the results of the Dixième Année show that, given an adequate degree of motivation, it is by no means too late to immerse into another language at age 15 or $16 .{ }^{13}$ What is needed on the part of the students, however, is a willingness to overcome initial difficulties, a period which, 
according to the introductory information leaflet, may last for several months.

4) The tenth school year lies outside the mandatory school time. The qualifications necessary for further education or certain apprenticeships ${ }^{14}$ are no longer affected by potentially weak performance due to schooling in another language than one's own mother tongue. Therefore no objections were made at the symposium to the adoption of such a model; in fact, representatives from the EDK suggested it for nationwide implementation.

One interesting side effect could be observed when we evaluated the questionnaires, i.e. the relativization of stereotypes. In many cases the response to the question 'Has this year changed your attitude towards your compatriots across the language border?' was either 'Yes, for the better' or 'No, because it was already positive to begin with' (cf. Appendix to Latscha and Andres 1988: 75ff.).

\subsubsection{Bilingual Schooling in preparation for higher education: The Lycée Franco-Allemand in Buc (France)}

The pupils of the Lycée in mainly middle class Buc near Versailles are both of French and German mother tongue and receive their schooling alongside each other. The two language groups are, however, taught in separate classes except in some subjects like music, arts, sports and English. The program starts in what is called CM2, in other words, the fifth school year and continues until the Terminal, the last school year, at the end of which the students sit for their baccalauréat or their Abitur. An important part of the curriculum is an intensive program in the partner language, German for francophones and French for German speakers of 6 to 8 hours per week. These lessons take place in small groups. In addition to this program some non-language subjects are also taught in the partner language, i.e. Geography for four years, History for one and a half years and Biology for one year.

The Lycée Franco-Allemand offers a bilingual program taking students all the way to their school-leaving exams. Like Goffs, the school prides itself on providing its students with qualifications which open the path to the so-called 'grandes écoles' (prestigious universities like the Sorbonne). Therefore, it is fairly obvious that great demands are made on the pupils. Although only a comparatively small number, approximately $10-20 \%$ 
according to headmaster Piton, will be 'bilingual' at the end of their school career, the level of competence in the second languge across the board is considerbly higher than that of students with a comparative (lycee) education in the other national schools.

According to Piton, the level of mother tongue competence with the German-speaking students is as high as that of monolingually trained students, which would indicate that this type of second language-oriented school system does not seem to have an adverse effect on the pupils' first language competence (cf. also the result from French immersion in Canada, for example Cummins and Swain 1986).

The Lycée Franco-Allemand was selected as an example for those French and German lycées/Gymnasien which offer bilingual courses and aim at bilingual end-of-school exams, i.e. the baccalauréat or the Abitur. ${ }^{15}$ The suggestion was that, in Switzerland, the standing of the recently introduced Gymnasium type D (cf. note 28 in Andres, this issue) could be improved if it were modified along the lines of the bilingual lycées/Gymnasien. At present, as one of the educational administrators pointed out at the symposium, type $\mathrm{D}$ is considered not to be demanding enough in comparison with other types. Introduction of bilingual instruction would therefore re-adjust the balance. The problem may be, however, that the Maturitäts-Anerkennungsverordung (cf. Keller, this issue) would have to be amended as it does not yet contain a provision for bilingual maturité exams.

\subsection{Results of the symposium}

\subsubsection{Necessity for further improvements in LN2 competence}

What the models had shown was that there are several ways in which bilingual education could be implemented and that an eclectic approach would yield a number of practicable possibilities for the Swiss school system. Furthermore, there was a consensus that more needed to be done to improve LN2 communicative competence for four reasons:

- Stereotypes and prejudices concerning one's compatriots exist in all language regions. Class exchange and immersion school models (Dixième Année) show promising signs that such preconceived notions can be put into perspective or eliminated.

- Despite a comparatively low level of unemployment and a surplus of 
open positions at present, the possibility, in some cases the necessity, exists for internal migration in order to find suitable employment. Industrialists have long demanded that mobility be considered as a means of preventing localized un- or underemployment. As the country is fairly small, there is a likelihood that migration will mean crossing language borders. In order to be able to do that, the two more dominant language groups, the German speakers and the French speakers, need at least a workable competence in LN2 (as most Romansch and Italian-speaking individuals already have). Bilingual education could aid mobility across the language borders.

- Although Switzerland is not a member of the European Community, it will be affected by the move towards greater unity in 1993. In terms of language choice in the Community, English is bound to play a major role. However, because of the size of the French language community across the world, it is unlikely that the francophone nations will be prepared to see their language marginalized. There is likely to be a very strong lobby to give French an equally central status in the Community. The same could apply, although probably to a lesser extent, to German. As a consequence, the need to learn French and German in Europe is likely to increase, rendering communicative competence in either language important for other reasons (economic, political, etc.) than 'merely' those of intranational communication. ${ }^{16}$

- There is agreement that successful bilingualism, especially in languages with a high prestige, is usually accompanied by a high degree of language awareness (cf. for example Miller 1983; Cummins and Swain 1986). As the tertiary economic sector is gaining in importance in Switzerland, it is evident that a high degree of language awareness is needed to cope with the demands of modern life. Bilingual schooling as envisaged by the project could be a means to that end.

On this basis communicative competence in LN2 needs further improvement, but it is questionable whether the existing system can provide the most adequate framework for the needs of all learners. Those who require a high degree of functional bilingualism for occupational or sociocultural reasons are likely to continue to experience the limits of the traditional type of second language teaching which treats the LN2 as a curricular subject rather than a means of communication and exploration. The project group argues that by integrating the LN2 into a general concept of pedagogy, the scope and efficiency of LN2 tuition can be 
increased considerably. Given a cooperative and exploratory approach to subject matter, the learners are likely to use language for a greater variety of purposes. In interaction with fellow learners and the teacher they will have to make use of and expand their communicative competence as they go along.

As explained above in section 2, communicative competence is here seen as consisting not only of institutionalized knowledge that, theoretically at least, could be learnt via teacher input and intellectual study of rules and principles, but also of emergent aspects that can only be acquired via intensive practice in meaningful situations of communication; or, as John Gumperz puts it,

as the result of a speaker's actual interactive experience, that is, as a result of an individual's participation in particular networks of relationships. (Gumperz 1982: 15)

Although it is admitted that in an immersion model such 'networks of relationships' are confined to the immediate social context of the school, making the LN2 the classroom medium of communication nevertheless expands the scope of interactive experience considerably.

As the models discussed at the symposium have shown, there is a further vital aspect that needs to stand at the center of our attention; it is best clarified with the example of the Dixième Année Linguistique. There we observed two groups of learners with diverse motivations taking part in the program and equally incongruous success rates. The example shows that the beneficiaries of immersion models ought to have a clear sociocultural and/or socio-economic purpose for taking part. Clearly, in areas along the linguistic borders such purposes are more likely to be given, and individuals who would like to see themselves as playing the role of language brokers are more likely to bring along such a motivation. The other illustrative example, that of the Ecole La Tanne, further supports this point in that those students' motivation is even more firmly entrenched in the dual purpose of maintaining their religious and cultural identity while at the same time opening up avenues of economic opportunity, which are accessible only through the vehicle of French.

With respect to the second major project aim, that of improving the rapports between the nation's speech communities, the project group ought to counteract the danger that, as in Canada, bilingual education becomes the preoccupation of the representatives of the linguistic majority who hence empower themselves to the detriment of the minorities. 
This aim can best be reached by parallel initiatives from all language groups in Switzerland.

The project group, it was felt, should therefore continue in its efforts to research models of bilingual education and to assist in their realization.

\subsubsection{Further research}

Further research is needed on two levels, firstly, on national language contact and language conflict situations, and secondly, in terms of the implementation of bilingual school models.

On the national level, research must be conducted into the nature of language contacts, preconceived notions and stereotypes, their underlying causes and what could be done to eliminate them. Here, we need to coordinate our own activities with research already under way and completed. ${ }^{17}$

Preparatory research for the implementation of bilingual models of schooling is a necessity in view of the presentations by Heller and Nelde (cf. Heller, Nelde, this issue). Detailed ethnographic analysis should, on the one hand, reduce the risk of repeating some of the errors made elsewhere, and, on the other hand, ensure that the models envisaged for realization take into account the exigencies of the region in which they are to be implemented. The importance for the latter must not be underestimated in view of the strong regionalism discussed in the article on language relations in multilingual Switzerland (Andres, this issue).

Obviously the needs of bilingual education differ markedly from those of monolingual schooling in terms of materials and teacher training. An entire infrastructure for these aspects needs to be set up here, since teachers already working in bilingual school systems, either at Ecole La Tanne or for the Dixième Année, do not receive any formal assistance in their work. In practical terms, this will mean close cooperation with experts from abroad, with academic disciplines related to multilingualism and schooling, and with the agencies of the education authorities concerned with teacher training and the production of materials.

\subsubsection{Envisaged further action}

The project involves a number of academic disciplines, from linguistics to sociology. Research has been and is being conducted in various institu- 
tions, but there is as yet no infrastructure for teacher training and the production of materials. Implementation requires the support of parents, teachers, school administrators and education authorities.

Taking all these aspects into consideration, we must maintain and/or seek broadly based cooperation in several directions: with representatives from other university departments and faculties on the interdisciplinary level; with other universities and institutions furthering intranational contacts to coordinate research; with experienced circles from abroad with respect to teacher training and the production of materials; and, last but not least, with educationalists as well as teacher and parent organizations to set up schools offering bilingual education.

One of the conclusions reached at the symposium was that a Swiss version of Early Total Immersion, although certainly of interest, would have to be a more long-term goal. Cautionary voices, both from Switzerland and abroad, have led to the realization that this system is not the panacea for difficulties in communication across the language borders. Other systems might achieve good results without the financial and structural efforts needed for a total immersion program.

The practical results of the debate concerning possible models yielded the following initiatives:

- The EDK sees the Dixième Année Linguistique as a model which could be realized fairly easily as it would merely require remodeling some of the exchange organizations already in operation ( $\mathrm{CH}$-Stiftung für Jugendaustausch, National Foundation for Youth Exchanges).

- In some schools near the language border the introduction of LN2 as the medium of instruction for some non-language subjects is under discussion with a possible realization in the school year of $1990 / 91$. The language border is the focus of this effort because mother tongue teachers can take over such courses without having to move to a different part of Switzerland (and a different language area).

- Some private schools have started developing contacts with a view to the possibilities of institutionalizing the exchange of teachers and/or classes. Another suggestion was to exchange half the students in one class, thus creating a communicative need for the students to use an LN2 also amongst themselves and outside the class room. ${ }^{18}$

For the following suggestions no practical steps have been taken as yet. They were, however, considered feasible:

- To improve the status of type D Gymnasien a system modelled either on Goffs School or on the Lycée Franco-Allemand was suggested. 
- In those Swiss towns with a high proportion of speakers of another language bilingual day-care centers and play schools/kindergartens could be set up.

- In Switzerland special schools are planned for children with artistic talents or potential in sports. Could not the same be done for children with a need or an obvious ability to learn languages?

\subsection{The future of the project}

The immediate task for the coordination team will be to publicize the idea of language immersion programs for schools in a society which, contrary to common ideas about Switzerland, still needs to be convinced that improved functional bilingualism is a goal worth working towards. The task is helped by the fact that the EDI-report is aware that immersion might be one answer to some of the language contact problems in Switzerland (EDI 1989: 393).

Another problem, which will have to be addressed, is that of Italian as a possible target language for bilingual education. ${ }^{19}$ Such an effort could help to curb the trend towards the marginalization of Italian in Switzerland, but it would also offer one way of integrating Italian-speaking immigrant workers, still the largest contingent, more efficiently.

University of Berne

\section{Notes}

1. In our opinion there are two additional factors to be taken into consideration. Firstly, linguistic findings make their way fairly quickly into EFL class materials, but take much longer to 'percolate' into textbooks for other languages. Secondly, the market for EFL materials is much bigger with more variety and competition. As a result EFL materials have a more attractive and modern appearance and have been more oriented towards communicative skills. In contrast, many of the German and French course books still in use seem antediluvian in their methods (traditional grammar-oriented or strongly audiovisual), objectives (writing and literature in preference to oral communication) and themes (basically stodgy, lifeless middle-class settings with little action of interest).

2. In the context of communication the term 'floor' means, in everyday usage, 'the attention of an audience; broadly: the right, esp. of a member, to address an assembly' according to Webster's Third International Dictionary.

3. The Canale-Swain conceptualization of communicative competence underlies a largescale, five-year study of Canadian French immersion students, carried out at the 
Modern Language Centre of the Ontario Institute for Studies in Education. The aim of the first part of this study was to determine whether the three hypothesized components of the construct of communicative competence could be empirically distinguished on the grounds of a battery of language tests. However, the statistical factor analysis failed to confirm this three-component structure of proficiency in a second language (Harley et al., 1987). Bachman, in an invited critique, objects that the 'actual measures themselves consist of a mixture of diverse abilities' (1988: 47), so that each component may have tapped a richer variety of abilities than were hypothesized by the model. Schachter (1988) offers some even more serious criticism; basically her position is that linguistic theory is not ready yet to offer a conclusive distinction between the components 'grammar', 'discourse', and 'pragmatics'. Both criticisms attest to the fact that many of the 'abilities for use' in the individual modules are determined by abilities assigned to other modules. For instance, grammatical competence, or aspects of it, is often dependent on features of sociolinguistic competence.

4. The term, although not relating to an established discipline, has gained some official currency in recent years. For instance, it is used as a series title (Studies in Interactional Sociolinguistics, Cambridge University Press), and it appears as a section title in Wolfson's recent textbook Perspectives: Sociolinguistics and TESOL (1989: 156).

5. However, this idea presupposes that there are ways and means to overcome the traditional teacher-centeredness inherent in immersion programs. Since the teacher knows the LN2 best, he or she is likely to dominate the discourse even more than in situations where both learners and teacher interact in their L1.

6. The initials stand for 'Réalisation pour l'enseignement multilingue international'.

7. The success and the economic viability of this scheme must probably be seen in the environment of the 'international city' of Geneva, where there is a greater demand for language tuition at an early level albeit not necessarily in one of the national languages.

8. As yet our data on the Mennonite school in La Tanne are somewhat limited, but we hope to examine the conditions and the achievements of the pupils in greater detail through a research grant from the Office for Pedagogical Research of the Education Authorities in Berne.

9. Two lessons of geography in the first year of the program (year 3 of French) and two lessons of general studies in the second (year 4).

10. ' $A$ ' levels are normally taken two years after ' $O$ ' levels, i.e. approximately at the age of 17 or 18 . Three 'A' levels are required for entry to university.

11. Originally an exchange of classes was organized between the two cantons and the system worked so satisfactorily that it was decided to institutionalize the exchange. This class-exchange program is still in place, but the exchanges are too sporadic to be of interest here.

12. The terms are used in Lambert's sense here (1967: 102ff.).

13. Cf. the encouraging results of Late Immersion programs in Canada (e.g. Harley 1986).

14. In Switzerland entry to certain apprenticeships is dependent on the level of secondary schooling.

15. The school was visited by a member of the project team in Summer 1988 with a view to presenting the model at the symposium. Unfortunately the headmaster as well as the deputy head were prevented at the eleventh hour from actually participating, but the model was discussed as a possible basis for implementation in Switzerland.

16. In the run-up to the referenda concerning Early French in Zürich, St. Gallen and Thurgovia, one of the arguments against the measure was that it was being enforced merely to conform to a federal policy to the detriment of the children (Andres 1988: 43).

17. Such contacts would be National Science Foundation Project 21 (Multiculturall 
Switzerland) on an interuniversity level, or the Foundation for Federal Cooperation as a partner for general contacts.

18. One voice of concern was that most immersion models of bilingual education tend to reverse the trend from learner-centered to teacher-centered forms of instruction. This would not be the case with semi-class exchanges.

19. Such steps are being taken by the education authorities in the canton of Zürich, where the Liceo artistico was opened this year. The Liceo uses Italian as a means of instruction and aims at end-of-school exams recognized by Swiss and Italian institutions of higher education.

\section{References}

Andres, Franz

1988 Die Frühfranzösisch-Kontroverse. In Verena Latscha and Franz Andres (eds.), 39-45.

Bachman, Lyle

1988 Constructing measures and measuring constructs. In Harley et al. (eds.), 39-62.

Bundesverfassung der Schweizerischen Eidgenossenschaft

$1874 \quad$ Stand 1.4.89.

Canale, Michael and Merrill Swain

1980 Theoretical bases of communicative approaches to second language teaching and testing. Applied Linguistics 1: 1, 1-47.

Cummins, Jim and Merrill Swain

1986 Bilingualism in Education: Aspects of Theory, Research and Practice. London

Dürmüller, Urs and New York: Longman.

1989 Englisch in der Schweiz. In EDI (ed.), 1-14.

EDK (Konferenz der kantonalen Erziehungsdirektoren)

1974 Berichte und Anträge. Bern.

1987 Herausforderung Schweiz. Materialien zur Förderung des Unterrichtes in den Landessprachen. Bern.

EDI (Eidgenössisches Departement des Innern)

1989 Zustand und Zunkunft der viersprachigen Schweiz. Abklärungen, Vorschläge und Empfehlungen einer Arbeitsgruppe des Departementes des Innern. Bundeskanzlei: Bern.

EDI (ed.)

1989 Materialienband zum Schlussbericht der Arbeitsgruppe zur Revision von Artikel 116 der Bundesverfassung. Bundeskanzlei: Bern.

Erickson, Frederick

1986 Listening and speaking. In Deborah Tannen and James Alatis (eds.), Georgetown University Round Table on Languages and Linguistics. Washing-

Fillmore, Charles ton D.C.: Georgetown University Press, 294-319.

1979 On fluency. In C. Fillmore, D. Kempler and W. Wang (eds.), Individual Differences in Language Ability and Language Behavior. New York: Aca-

Fishman, Joshua demic Press, 85-101.

1972 Societal Bilingualism: Stable and Transitional. In A.S. Dil (ed.), Language in 
Gibson, J.

Sociocultural Change. Essays by Joshua H. Fishman. Stanford: Stanford University Press, 135-152.

1984 For my kids, its French without tears. In Max Yalden (ed.), The Immersion Phenomenon. Language and Society 12. Ottawa: Minister of Supply and Services, 8-10.

Gretler, A.

1989 Das schweizerische Bildungswesen unter dem Blickwinkel der Sprachen-

Grosjean, G. problematik - Sprachunterricht in der Schweiz. In EDI (ed.), 15-52.

1971 La carte historique de la Suisse. Bern: Kümmerly and Frey.

Gumperz, John

1982 Discourse Strategies. Cambridge: Cambridge University Press.

Harley, B.

1986 Age in Second Language Acquisition. Clevedon: Multilingual Matters.

Harley, B., P. Allen, J. Cummins, and M. Swain

1987 The Development of Bilingual Proficiency. Final Report. Volumes I-III. Toronto: Modern Language Centre, Ontario Institute for Studies in Education.

Harley, B. P. Allen, J. Cummins, M. Swain (eds.)

1988 The Development of Bilingual Proficiency. Toronto: Modern Language Centre, Ontario Institute for Studies in Education.

Heller, Andreas

1987 Beim Sprung über den Graben refüsiert der Schweizer. Die Weltwoche 3/87.

Heller, Monica and Graham Barker

1988 Conversational strategies and contexts of talk: learning activities for Franco-

Ontarian minority schools. Anthropology and Education Quarterly 19: 1, 20-47.

Hymes, Dell

1972 On communicative competence. In J. Pride and J. Holmes (eds.), Sociolinguistics. Harmondsworth: Penguin, 269-293.

Lambert, Wallace

1967 A social psychology of bilingualism. Journal of Social Issues 23: 2, 91-109.

Latscha, Verena and Franz Andres (eds.)

1988 Unterrichtssprache Französisch/Deutsch. Einführende Texte zum Symposium.

Koordinationsstelle für das Projekt 'Unterrichtssprache Französisch/Deutsch'.

Miller, Jane

Bern: Mimeograph.

1983 Many Voices. Bilingualism, Culture and Education. London: Routledge and Kegan Paul.

Pichard, A.

$1978 \quad$ Land der Schweizer. Eine Beschreibung der Schweiz und schweizerischer

Schachter, Jacqueline

Eigenart (und Unart). Frauenfeld: Huber.

1988 Communicative competence revisited. In B. Harley et al. (eds.), 63-81.

Wolfson, Nessa

1989 Perspectives. Sociolinguistics and TESOL. Cambridge: Newbury House.

Zeitz, A.

1989 Die viersprachige Schweiz. Bildungspolitische Herausforderung und pädagogische Chance. Die Neueren Sprachen. Themenheft Wege zur frühen Mehrsprachigkeit 88/4, 345-369. 